\title{
Who Mediates? The Political Economy of International Conflict Management*
}

\author{
JACOB BERCOVITCH \\ Department of Political Science, University of Canterbury
}

GERALD SCHNEIDER

Faculty of Public Policy and Management, University of Konstanz

\begin{abstract}
Studies on international mediation have traditionally focused on the effectiveness of international efforts to settle or resolve militarized conflicts. In this article, we start from a different perspective and examine the identity of mediators and the factors determining the choice of mediators. We build an integrative theoretical framework to explain the number of mediation mandates an international actor receives. The hypotheses we derive are subsequently tested in a multivariate event count model using an original dataset on international mediation from 1950 to 1990. The results obtained from Poisson and negative binomial regressions disconfirm the assertion that the effectiveness of a mediator influences the number of mandates it receives. The most important structural force on the international mediation market seems to be the hegemonic status of the USA. The analysis further demonstrates that international conflict management is largely, but not exclusively, restricted to the permanent members of the Security Council of the UN. As the theoretical framework suggests, ideological factors, such as the neutrality of the mediator, play a less significant role on the market for mediation. Democracies equally are not significantly more active than autocracies in the management of international conflicts.
\end{abstract}

\section{Introduction}

Matching mediation offers with parties

\footnotetext{
* This article was originally presented at the American Political Science Association Annual Meeting in Boston, 3-6 September 1998, the Third Pan-European Conference in International Relations, Vienna, Austria, 16-19 September 1998, and at a research seminar at the University of Konstanz, July 1998. We have received helpful suggestions from three anonymous reviewers from $J P R$, Scott Gates, Nils Petter Gleditsch, Pat James, Torsten Selck, and other conference participants. The article is based on a government evaluation report that the second author has written with Lionel Marquis (University of Geneva) and which has subsequently been published in an abbreviated version (Marquis \& Schneider, 1996). Tamas Golya, Oliver Kämpf, Judith Polnik, and Ismet Yigit (Institute of Political Science, University of Stuttgart) collected the data on mediator characteristics which are used in the systematic extension of the preliminary study. Tobias Bachteler (University of Konstanz) assisted in the data analysis. The dataset analyzed in this article can obtained from: http://www.uni-konstanz.de/FuF/Verwiss/GSchneider/.
}

requiring the assistance of a third party is by no means a straightforward exercise. Often, this process resembles the cumbersome task of finding an acceptable attorney in a seemingly hopeless criminal case. The difficulties in finding an appropriate conflict manager became obvious when the conflict between the USA and Iraq escalated in February 1998. In the early phases, several states volunteered to act as mediators. However, none of these offers was accepted by the disputants. In the very last minute, when a confrontation seemed inevitable, the Secretary-General, Kofi Annan, offered his services and, somehow, was accepted.

This last-minute selection of a mediator is only one of the outcomes that we can observe. While certain mediation mandates 
wander from one third party to another, like a hot potato, in other conflicts a regular mediator travels from one capital to another in the often vain attempt to bring peace to a certain region. Although this form of shuttle diplomacy still plays an all too important role in international politics, we do not understand the mechanisms through which certain conflicts become amenable to thirdparty intervention, nor do we understand the reasons why certain parties are chosen again and again as mediators. Most studies on international conflict management focus on the success of these mediation attempts. To our knowledge, no study has been undertaken that systematically examines the recurrence of certain mediators in international conflicts. This neglect is surprising since most policymakers would be keen or interested in the prestige that they could gain from successful mediations.

One example of the standing that mediators could gain is the celebrity status of the Norwegian diplomats who facilitated the Oslo peace process. Other examples include New Zealand's self-proclaimed role as a South Pacific mediator following its success in the Bougainville conflict, and the behavior of the Swiss government which created a myth around its role in bringing the Algerian independence movement and the French government to a peace agreement (Marquis \& Schneider, 1996). In the USA, some commentators have noticed that American presidents are more likely to embark on peace missions around the globe when they need to bolster up their domestic popularity (e.g. Ninic, 1992).

Unfortunately, we do not know the reasons why certain actors become more active in the mediation market, nor whether features such as impartiality are an important asset in a mediator's inventory of attributes. This article tries to rectify this situation. It offers the first theoretical and empirical analysis of the supply of mediators in international conflicts. In particular, we wish to examine the range of structural factors and attributes that make some countries mediate so often, while others hardly ever gain access to the mediation market. The empirical analysis is based on the mediation dataset that has been created by the first author and which Goertz (1997) subsequently linked to the Militarized Interstate Dispute (MID) dataset.

The article is structured as follows: first, we discuss the theoretical insights that can be gained from the literature on international mediation. We then move to a presentation of an expected utility model from which we derive the hypotheses that are subsequently tested. The empirical section starts with a descriptive analysis of the number of times that states and international organizations have been active in the international mediation market. Next, we present the results from the multivariate event count models which is the adequate method for the kind of data we are analyzing (Cameron $\&$ Trivedi, 1998). The article concludes with a discussion of how the choice and range of mediators affects international conflict management outcomes.

\section{The Supply of Mediation: Theoretical Considerations}

The range of possible actors in the mediation market is truly immense. Many of the actors in the global environment may engage in formal or informal mediation. To make sense of the range of mediators we suggest that they all fall within one of the following three categories: (i) individuals, (ii) states, and (iii) institutions and organizations, be they governmental or nongovernmental. Let us briefly examine the characteristics of each category of mediators.

\section{Individuals}

The traditional image of mediation, one 
nurtured by the media and popular accounts, is that of a single, usually highranking, individual, shuttling from one place to another, trying to search for understanding, restore communication between hostile parties, or help settle their conflict. This image is only partly accurate. The individual mediator who engages in such behavior is normally an official representing a government in a series of formal interactions with high-level officials from the disputing countries. The encounters may be of an individual kind (as all political interactions ultimately are), but we must not lose sight of the consequences of formal representation, nor should we attempt to explain complex phenomena in terms of the one easily visible component, namely, the individual. When President Carter brought Prime Minister Begin and President Sadat to Camp David, there was much personal interaction, but no one could possibly describe the whole experience as individual mediation.

By individual mediation, we mean mediation that is carried on by individuals who do not fulfil an official, representative function (examples of such mediations include Carter's efforts in Haiti and Korea, Francis Noel-Baker in the Cyprus conflict, or Elsworth Bunker in the West Irian conflict). Obviously, individuals mediators may differ with respect to the nature and level of their capabilities and resources, their ability to perform the required tasks, knowledge, skills, experience, and other attributes. They may also hold different beliefs, values, and attitudes. These affect the objectives they seek and their range of options in mediation. The mediation strategies of individuals are more directly related to their capabilities and subjective experiences, than to the external and contextual stimuli that impinge on them. Individual mediation can therefore exhibit greater flexibility and experimentation than mediation by political incumbents.
Yet, despite these potential merits, individuals per se are hardly the dominant actors in the mediation market. Most mediation activity is carried on by two kinds of actors, states (or to be more accurate, their representatives), and international organizations.

\section{States}

As a political actor, the state remains, despite the globalization of international politics, one of the most successful and enduring forms of social and political organization. Today, some 195 sovereign and legally equal states, but with different capabilities, regime-structures and interests, interact on the international arena. They pursue resources and markets, and peddle for influence. Often, they get into conflicts with other states pursuing similar objectives. When this happens, representatives of states get together in any of the myriad of international forums to articulate their concerns and search for a settlement - through mediation or other means.

When a state is invited to mediate a dispute, it normally engages the services of one of its top decisionmakers. In these cases, figures such as President Carter, Secretaries of State Albright, Baker or Kissinger, or British Foreign Ministers Lords Carrington or Owen, fulfilled a mediatory role, in the full glare of the international media, as salient representatives of their countries. International mediation by such individuals is shaped by (i) the position they hold in their own country, (ii) the leeway given to them in determining policies, and (iii) the different resources, capabilities, and political orientations of their countries.

Representatives of all states formally interact in the various international policymaking bodies. But trying to penetrate beyond the myth of formal representation and legal equality, it is legitimate to wonder to what extent do differences in the level of 
resources impinge on the number of times a particular state mediates. Are differences between states significant in the mediation market, or are they cancelled out by the formal context? We believe these differences are crucial to mediation success, and should be examined in greater detail.

\section{Institutions and Organizations}

The complexity of the international environment is such that states and nations can no longer facilitate the pursuit of human interests alone, nor completely satisfy their demands for an ever increasing range of services. Consequently, we have witnessed a phenomenal growth in the number of international, transnational, and other non-state actors, all of whom affect issues of war and peace, knowledge and responsibility, and environment and survival. These functional systems of activities or organizations have become, in some cases, more important providers of services than states. They have also become, in the modern international system, very active participants in the search for institutions and proposals conducive to peace. We would expect such organizations to play their full part in the mediation of international disputes.

Three kinds of ideal type organizations are important to our understanding of international mediation. These are: (i) multilateral ad hoc teams, (ii) international organizations, and (iii) transnational nonstate organizations. International organizations represent regional or global collections of states signifying their intention to fulfil the obligations of membership as set forth in their formal treaty. Transnational organizations, by contrast, represent individuals across countries who have similar feelings, cognitions, knowledge, skills or interests, who meet together on a regular basis to promote the special interests of their members. Since transnational organizations are 'nongovernmental' in origin, they can afford to be more creative and less inhibited in the policy positions they advocate than international organizations. By consequence, this type of organization embodies many of the elements commonly associated with impartiality. Does this suggest that transnational organizations are more likely to be chosen as mediators? Or would their mediatory role be somewhat circumscribed by the lack of an adequate resource-base? And, come to that, do discrepancies in context and formal structure affect the selection of mediators?

\section{Attributes of Mediators}

Which of these international actors receives the most mandates to negotiate a peaceful settlement? In her systematic review of the literature, Kleiboer (1996) identifies most of the attributes and structural factors which are conducive to successful mediation. Can we infer from this that actors possessing the requisite attributes will be called upon to mediate repeatedly? And, if we can identify these attributes and structural factors, can we examine them empirically? We believe we can, and intend to do so below.

A political actor is more likely to be asked to mediate when it is perceived as reasonable, acceptable, and knowledgeable. Wehr (1979), in a theoretical discussion, lists the required attributes for mediators to include: knowledge about conflict situations, ability to understand the positions of the antagonists, active listening, a sense of timing, communication skills, procedural skills (for example, chairing meetings, etc.).

The list of desired mediator attributes is very long. Among the factors that experienced international mediators cite as particularly important are intelligence, stamina, energy, patience, and a sense of humor (Bercovitch, 1984). Such personal qualities are associated with success in other areas of human endeavor; they are, of course, no less 
important in international mediation. Trust, credibility, and a high degree of personal skill and competence in a mediator are also necessary preconditions for mediators' acceptance and successful mediation (Karim \& Pegnetter, 1983). In much the same vein, Young argues that intellectual dexterity and persuasiveness in dealing with such problems as the transmission of information ... are apt to be more important determinants of success than the possession of any instruments of physical coercion' (Young, 1972: 56).

Another characteristic that has traditionally been cited in the literature as being strongly associated with the choice of mediators, and even their effectiveness, is evenhandedness, or neutrality. Young claims that 'a high score in such areas as impartiality would seem to be at the heart of successful interventions in many situations' (Young, 1967: 81). And his views are echoed by others (Jackson, 1952; Northedge \& Donelan, 1971), who claim that parties will have confidence in a mediator only if he/she is, and is perceived as, neutral. Elmore Jackson, himself an experienced international mediator, makes this quite clear: 'It would be difficult, if not impossible, for a single mediator, who was distrusted by one of the parties, to carry out any useful function' (Jackson, 1952: 129). More recently, Princen (1992) and Kaufman and Duncan (1992) emphasize the importance of neutrality in the selection and acceptability of mediators.

It seems to us that the emphasis on neutrality stems from a failure to recognize mediation as an aspect of social interaction in which the mediator is a major participant with distinct interests. It is entirely sensible to see mediation as 'assisted negotiation' (Susskind and Cruickshank, 1987). A mediator engages in behavior that is designed to elicit information and exercise influence. Mediators are accepted by the adversaries not because they exemplify an antidote to bias, but because of their perceived ability to influence, protect, or extend the interests of each party in conflict (Faure, 1989; Kressel \& Pruitt, 1989; Smith, 1985; Touval, 1985; Touval \& Zartman, 1985). We wish to argue that mediators are asked to mediate because they are seen as being capable of promoting an agreement through the use of leverage, power potential, and influence, and not because their protestations of neutrality (see Regan, 1996).

To exercise influence and structure the interactions between the parties, mediators need 'leverage', understood as a wide array of means, and resources. Leverage and resources enhance their ability to achieve a favorable outcome. Mediators' objectives are twofold; to change the physical circumstances of a conflict (e.g. to get parties to meet in a different environment) and to shape the nature of the outcome (Edmead, 1971; Frei, 1976; Gross-Stein, 1985; Touval \& Zartman, 1985). These objectives are best achieved, as Zartman and Touval (1985) observe, not when a mediator is unbiased or neutral, but when he/she possesses resources that either party values (e.g. political support, economic resources). The choice of one mediator out of many possible ones is thus a matter of resources, leverage, and potential influence (Brookmire \& Sistrunk, 1980).

Mediators enter a variety of conflict situations; some between sworn enemies, others between friends. They mediate conflicts over territory, economic resources, ideological differences, independence, amongst other issues. In all these instances, they have to modify, affect, or change parties' behavior or expectations. To achieve this, mediators need a variety of means and resources at their disposal. Reasoning, logic, and neutrality may go some way toward influencing the parties, but those likely to mediate more often will be mediators who can rely on a 
broader array of resources. Mediators who can promise support (or conversely, threaten to withdraw it), are more likely to produce an agreement than other mediators, and therefore will be in greater demand as mediators. We would expect to see them mediate more often than other actors.

An important resource that may help mediators influence the parties is their legitimacy. Legitimacy is derived from the structure of a relationship. Leaders of states and high-level officials, such as foreign or prime ministers, have legitimacy and can bring it to bear in their mediation efforts (Ott, 1972; Touval \& Zartman, 1985). High-ranking mediators carry more legitimacy, and can more easily establish an environment of credibility and trust. The presence of highranking and legitimate mediators allows the parties to back down from fixed positions, make concessions, and 'save face'; (Pruitt $\&$ Johnson, 1970). We therefore hypothesize that government leaders, high-ranking officials of large governments, or other actors who can provide tangible benefits or incentives, are more likely to mediate again and again.

Mediators' identity and the judicious usage of inducements, promises, threats, and incentives are but part of the picture. Two other factors influence the choice of a mediator: ideological position and cultural similarity. The literature on mediation is largely anecdotal with respect to these two factors. We see conflict management in general and mediation in particular as taking place within a system of values, beliefs, and interests. Mediators' efforts will be of little avail if they come from a totally different ideological background. Ideological position provides a kind of a safety net for all participants in conflict. When they have that safety net, they are more likely to engage in meaningful dialogue. There is some empirical evidence to suggest that mediators from the same bloc as the parties in conflict are more likely to be acceptable and effective than mediators from different blocs (Bercovitch, 1989).

In this article, we make the first effort to actually examine the effects of mediators' ideological position by operationalizing it through a country's position vis-a-vis the two Superpowers during the Cold War. We distinguish between states that were nonaligned, identified with the West, or aligned with the Soviet bloc. We assume that each cluster represents different ideological orientations. We would like to examine whether actors from within an ideological bloc are indeed more likely to be chosen to mediate conflicts within that bloc.

Another major influence that might affect the choice of mediators, and one which has received no systematic treatment, is culture, or cultural differences. Culture may be viewed as 'a system of meaning and values shared by a community informing its way of life and enabling it to make sense of the world' (Cohen, 1996: 109). When people from different cultures meet, such differences may result in misunderstandings, incorrect attributions, projections, and general confusion about significant values or symbols. Cross-cultural dissonance is particularly acute in international conflicts. When parties inhabit different cultural worlds, the prospects for successful conflict management are very slim (Arruch, 1998; Elgstrom, 1994).

Taking the notion of culture to international mediation, we would expect parties in conflict to more easily accept a mediator with a cultural background similar to their own. As there is no systematic research on this issue, we hope to break new ground by examining empirically the relationship between cultural similarity and the choice of mediators. Theses conjecture and the hypotheses we have discussed above are summarized in an expected utility model that we present in the next section. 
The Mediation Market: An Expected Utility Model of Mediator Selection

For various reasons, such as a constitutional mandate, prestige, or the desire to extend influence, governments and other actors like to act as mediators in an international conflict. Since the prospect of managing an international conflict is quite attractive even if no firm guarantee of success exists, it is not too far-fetched to speak of an international market for conflict managers. On the demand side, the market is largely controlled by conflict parties who have to agree on a mediator and jointly determine the price they are willing to pay to engage in mediation. This oligopolistic structure - in most cases a classic duopoly - is accompanied on the supply side by high competition amongst many actors, including states and some powerful international governmental organizations (IGOs). In this section, we want to analyze this market and introduce an expected utility model of mediator selection.

Although a political economy framework seems to be the obvious starting point for this kind of analysis, other perspectives dominate the mediation literature. The paucity of theoretically grounded studies is surprising, since the identity of a mediator may be a crucial determinant of the success of mediation. Here, we wish to examine empirically the variables mentioned in the previous section. These variables fall basically into three categories: (i) the power of a mediator, (ii) its ideological position, and (iii) its cultural and geographical proximity to at least one of the conflict parties.

Figure 1 places these variables within a wider theoretical perspective. We conceive of mediation as a process in which the selection of a mediator is an important step. Prior to that step, the conflict parties must agree that they should accept some form of third-party intervention in their conflict.

Figure 1. Mediation as a Three-Step Process

Agreement/Disagreement on mediation

\section{Choice of specific} mediator
Mediation outcome

\section{Explanatory}

factors

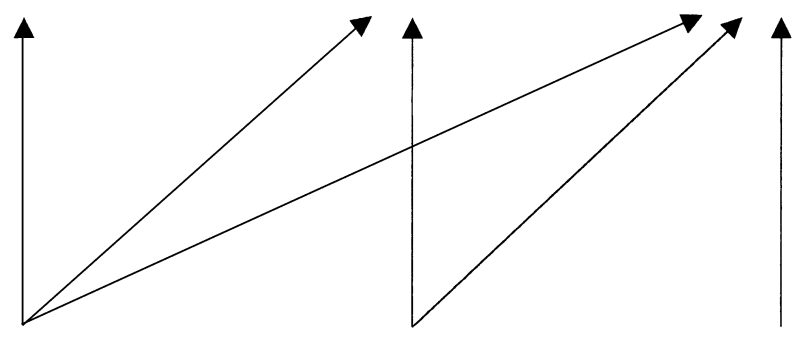

- Preferences and beliefs of conflict parties

- Capabilities

- Actor attributes

- Dyad attributes

- Structure of global and regional system

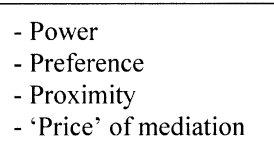

- Power

- Proximity

- 'Price' of mediation
- Strategies

- Skills

- Beliefs of

mediator 
Obviously, the nature of the conflict determines to a considerable extent the kind of mediator the disputants select, and the likelihood of success. The chances of success may also be influenced by the strategies and behaviors a third party develops in the course of its mediation mandate.

In this study, we will not focus on the entire mediation process, but rather on explanations for the number of times that an actor is selected as a mediator. Our theoretical explanation will thus treat enduring mediator attributes as explanatory variables, assuming that some features of an actor remain quite constant over time.

To study mediator selection in the aggregate, we have chosen an expected utility model as an analytic starting point. We assume that any kind of mediation effort is linked to fixed as well as variable costs which are both heavily influenced by the nature of the conflict itself. Obviously, a state will not even consider offering its mediation services if the fixed costs of a mediation attempt $c_{0}$ exceed the benefit of such an endeavor. Fixed costs basically consist of the price that an actor has to pay when it enters the mediation market. These comprise 'lost face', adverse publicity, or the administrative burden that mediation entails, but they also stand for the financial costs of recruitment and training of international conflict managers. The existence of fixed costs in mediation suggests that peripheral and poor states are less likely to enter the mediation market.

The variable costs $c$ partly include the disutility that might arise should mediation fail. The higher the level of activity, the larger these costs generally are. In other words, high-profile mediation is more likely to receive some of the blame if the parties do not settle their dispute. We also assume that a mediator's ideological position creates costs. If the mediator is perceived as leaning towards one of the conflict parties, the like- lihood of sanctions and ultimate failure looms larger. We assume that these costs grow with an increasing level of activity. It would be foolish to assume that a mediator is completely neutral towards the conflict parties before the conflict starts. Hence, the larger the distance between the final settlement and the mediator's own preference, the larger the disutility.

To summarize, the expected utility of a potential mediator in a two-party conflict takes the following functional form:

$$
\begin{gathered}
U(\text { Mediation })=c_{0}+a^{2} p s-(1-p) f \\
-\left(x_{0}-x\right)^{2}-a\left[\frac{x_{c_{1}}+x_{c_{2}}}{2-x}\right]^{2}
\end{gathered}
$$

where $c_{0}$ are a mediator's fixed cost, a represents the mediator's level of activity and $p$ stands for the probability that the mediation effort leads to some kind of settlement. The parameter $s(f)$ is the payoff on which a mediator can count in the event that the mandate is successful (not successful). All actors have a position $x_{\mathrm{n}} \in(0,1)$ on the zone of agreement, with $x_{0}$ being the ideal position of the mediator and xci standing for the preferences of the conflict parties.

We can easily calculate the optimal position and the optimal level of activity that a mediator will choose in a situation where the conflict parties are setting the price of the international conflict management activities. In the case of a two-actor conflict, the optimal ideological position of the mediator amounts to the following:

$$
x^{*}=\frac{x_{0}+a x_{\mathrm{n}}}{(1+a)}
$$

Note that a neutral position will only be chosen in case that a mediator is indifferent between the preferences of the conflict parties and chooses accordingly $x_{0}=\left(x_{\mathrm{c}_{1}}+x_{\mathrm{c}_{2}}\right) / 2$ as its ideal point. The mediator also tends to approach this position when he/she increases the level of activity. The analysis thus suggests that potential 
mediators, if they ever want to be chosen by conflict parties, move rationally towards a neutral position. This in-built tendency to behave neutrally explains the finding of Marquis and Schneider (1996) that formal neutrality policy does not make a state more attractive in the mediation market. Nevertheless, we will test the impact of formal neutrality and of a membership in the nonaligned movement on the number of mediation mandates. We expect that only the informal and more flexible form of neutrality will have a significant impact. Impartiality might also be a consequence of the experience that an actor has in the mediation market. The conflict parties might only trust those individuals or organizations with a track record in this business. This means that the likelihood of additional mediation mandates should increase with the number of times that an actor already belonged to the 'chosen few'.

The chance that a state will appear neutral is larger if it shares some background characteristics with the conflict parties. We will therefore test whether a similar regional background has any importance. In this respect, we include a variable that measures whether a mediator comes from the most conflict-ridden region of the world, the Middle East or not. Another variable that might affect the selection of mediators is the possibility that international conflict management is somehow perceived to be a Western tradition. This is the reason why we include a variable that describes whether or not a state belongs to the Western bloc. Finally, we will examine whether democracies are seen as more trustworthy mediators and thus more active in the mediation market.

Yet, it is not only the ideological position that matters. Conflict parties might also be concerned about the level of activity that they can expect from a potential mediator. In the eyes of the mediator, the reputational gain is optimized after the calculation of the first order conditions for $a$ :

$$
a^{*}=\frac{\left(x_{\mathrm{n}}-x\right)^{2}}{2 p s}
$$

We can derive from Equation (3) that the mediator's level of activity depends on the impartiality of his/her position. The more neutral the stance, the lower the profile of a mediator. The comparative statistics equally demonstrate that the anticipated gain and the probability of success, the less activities are needed. It is clear that a number of factors influence a potential mediator's ability to be successful; resources will undoubtedly be an important asset. We will test whether resource-aspects such as the population size of a state, or its economic power, are influential in the market for mediation. Another factor that we will examine is the hegemony argument which maintains that only a dominant state rather than an IGO is able to preserve peace and act as an international conflict manager (Lake, 1994). Accordingly, the theory of hegemonic stability maintains that benevolent actions of a pre-denominating power are key to the stability of the international system. Most authors now agree that the USA was the hegemonic power during the Cold War because the capabilities of the Soviet Union were exaggerated. This special status should be reflected in a higher likelihood of being chosen as a mediator. We can also argue that the regulatory monopoly granted to the cartel of states that hold permanent seats in the Security Council of the UN was also a significant hegemonic factor. Finally, some residual power might be a consequence of the colonial status of a state.

In order to make comparison among one set of mediators, we restrict our analysis to the number of times that a state has been a mediator between 1950 and 1990. Since we estimate a country's likelihood to be a mediator in the international market for 
mediation, the most general equation including all predictor variables takes the following functional form:

$\mathrm{N}_{\mathrm{I}}=\beta_{1}$ Council $+\beta_{2}$ West $+\beta_{3}$ Nonaligned $+\beta_{4}$ Middle East

$+\beta_{5}$ Hegemony $+\beta_{6}$ Colony $+\beta_{7}$ Neutrality $+\beta_{8}$ Population

$+\beta_{9} G D P+\beta_{10}$ Democracy + Constant $+\epsilon$

where $N_{\mathrm{i}}$ is the observed number of mediations by state $i, \beta_{\mathrm{k}}$ stands for the estimated parameter for the $k$ th variable, and Council represents a dummy variable coded as 1 if the state is a permanent member of the Security Council of the UN (0 otherwise). West takes the value of 1 if a country belongs to the Western Bloc during the Cold War (0 otherwise), while Nonaligned amounts to the value 1 if a country was part of the nonaligned movement ( 0 otherwise) and Middle East is 1 if a state is geographically located in the Middle East (0 otherwise). Hegemony and Colony are equally dummy variables coded as 1 for the USA (0 otherwise) and 1 for all colonial powers ( 0 otherwise) respectively. Neutrality is 1 for all formally neutral countries, Population measures the total population of the country in 1990, Democracy is the Polity III democracy score of a country (based on the openness of its political institutions, ranging from totally open democratic systems to closed military regimes), and Reputation is the average effectiveness of a state as a mediator, while $\epsilon$ stands for the stochastic or error term. How we test for the impact of reputation will become clear in the next section in which we discuss our research design and particularly the estimation methods.

\section{Method}

The statistical evaluation of the hypotheses that we derived from our equilibrium framework relies on event count models. Such models have a long tradition in biostatistical research and have been popularized in political science by King (1989a,b) and are more recently reviewed by Cameron \& Trivedi (1998). Recent applications of this methodology include studies on the occurrence of political violence (Krain, 1998) and the democratic peace (Benoit, 1996).

Event count techniques are appropriate in situations in which the outcome is a randomly occurring discrete event. The number of times that an actor is mediating in a militarized conflict obviously fall into this data category. Since the distribution of event variables are typically skewed, heteroskedastic, and, by definition, positive, ordinary least-square regressions tend to become inappropriate for the multivariate analysis of such occurrences. ${ }^{1}$

To estimate the occurrence of a particular event, researchers typically employ Poisson random variables as a starting point. This 'canonical' approach (Achen 1996) in event count statistics expects a rate $\lambda$ of events to occur during a time-period. In our study, we estimate the relative incidence rate of mediation mandates per state as the intensity of the predictor variables. Poisson regression models generally expect the log of the mean of $\lambda_{i}$ to be a linear function of the explanatory variables.

The standard Poisson model might, however, be unsuitable for the study of international mediation because it expects that different third-party interventions are not related to each other. In real life, however, some mediators might be more likely to be invited for a next round if some warring parties did already recognize their presence on the international mediation market and invited them to manage a conflict earlier. Obviously, in international politics as well as in any other social context, some actors are much more in demand than others.

${ }^{1}$ As King (1989a,b) has forcefully pointed out, the reliance on OLS can entail the estimation of negative parameters, which makes no sense as long as a count is the dependent variable. 
Whether the varying number of mediation mandates is a consequence of the power position an actor holds, or of more informal considerations such as experience or reputation, is a theoretical question that we will try to solve through a comparison of competing statistical models. The discriminating effect that previous experience might have on the potential attractiveness of a mediator some time later means, technically speaking, that the number of realized events in the past influences the expected number of events in the present. We therefore rely on another distribution, the negative binomial, to take such contagion effects into account.

The possible inter-relatedness of the occurrence rate of events would violate the assumption of the standard Poisson model, i.e. that the mean of the distribution has to be equal to its variance. The negative binomial, by contrast, expects 'overdispersion' in the data, implying that the variance exceeds the mean. On a theoretical level, overdispersion means that the likelihood of a mediator being reappointed depends on past experiences. If we include the variation parameter $\alpha$ as a predictor variable, we can control for this influence. The General Negative Binomial model controls for this influence while the Standard Negative Binomial model only estimates the size of the variance, adding an omitted variable $u_{\mathrm{i}}$ to the standard Poisson regression model.

Since we do not know whether reputation matters in the mediation market, we will compare the results that we obtain from OLS regressions, Poisson, and Generalized Negative Binomial event count models. The effect of reputation in the Generalized Negative Binomial model will be based on the mediator's average effectiveness on the mediation market. Given the complexity and uncertainty which may characterize the term effectiveness, we have decided to adopt a strictly behavioral approach (cf. Frei, 1976) and focus on the observed differences mediation has had on the parties' conflict behavior within a four-week period. Thus, we look at mediation outcomes in terms of four possible dimensions: unsuccessful, cease fire, partly successful, and fully successful. For purposes of our analysis, we group together the last three dimensions into a 'successful' category and contrast it with the other cases in the 'unsuccessful' category.

To examine the impact of reputation on the incidence ratio of an eventual mediator, we assume this parameter to influence the variation $\alpha$ of the observations. This means that more successful mediators should have a higher likelihood of being reappointed to another mandate in the mediation market.

\section{Dataset}

The outcome variable represents the number of times an international actor, and specifically a nation-state, received a mandate to mediate in an international conflict. Our empirical source is an expanded version of the mediator dataset which is the most extensive database on international mediation in the post World War II era. ${ }^{2}$ Our analysis relies on the version of the dataset that has been used by Goertz (1997) who included information on militarized interstate disputes to account for conflicts during which no mediation took place.

The analysis exclusively considers those cases where the parties accepted a mediation offer and such an effort was finally carried out. We added to the mediation dataset information on the profile of the mediators. First, we distinguished between different

\footnotetext{
${ }^{2}$ A number of earlier articles offer further information on this dataset and present some preliminary findings (Bercovitch 1986, 1989; Bercovitch and Wells 1993; Bercovitch et al., 1991) The data collection relied on two major events data sources, Keesings Archives and The New York Times. In assembling a list of disputes, we relied on the prior compilation of Small and Singer (1982), but lowered the threshold of fatalities to ten only. Thus, we define an international dispute as a continuous clash between two actors, at least one of them is a recognized state, and involving at least ten fatalities.
} 
Table I. Number of Mediation Mandates and Effectiveness of Conflict Management by Mediator Type, 1950-90

\begin{tabular}{lcc}
\hline Mediator Type & $\begin{array}{c}\text { Number of Mandates } \\
\text { (Relative Share in \%) }\end{array}$ & $\begin{array}{c}\text { Number of Successful Mandates } \\
\text { (Success in \% of all Mandates) }\end{array}$ \\
\hline Nation-states & $355(49.10)$ & $138(38.87)$ \\
IGOs & $272(37.62)$ & $93(34.19)$ \\
NGOs & $29(4.01)$ & $10(34.48)$ \\
Individuals & $38(5.26)$ & $10(26.32)$ \\
Nation-states/IGOs & $20(2.77)$ & $9(45.00)$ \\
Nation-states/Individuals & $2(0.28)$ & $0(0.00)$ \\
IGOs/NGOs & $2(0.28)$ & $0(0.00)$ \\
IGOs/Individuals & $2(0.28)$ & $0(0.00)$ \\
Others & $3(0.41)$ & $3(100.00)$ \\
Total & $723(100.00)$ & $263(36.38)$ \\
\hline
\end{tabular}

${ }^{1}$ If a specific actor mediated repeatedly within the same conflict, only one mediation is counted. ${ }^{2}$ This variable sums up the number of instances that a mediation attempt ended with a ceasefire, a full, or at least a partial settlement of the conflicts. Mediation offers that were not positively answered are excluded from the analysis.

types of actors - individuals, state representatives, IGOs, and nongovernmental organizations (NGOs). Mediators were considered to act on an individual base if they did not occupy a highly ranked official position in either the government or an international organization at the time of appointment. Hence, ambassadors, secretaries of state, prime ministers, and presidents were all considered to act on behalf of their government and not primarily in their own interest. We also formed different categories for mediator teams in which several different types of mediators unite: 'State and IGO', 'State and NGO', 'State and Private', 'IGO and NGO' and 'IGO and Private' are the mixtures that are empirically most relevant. ${ }^{3}$ The international Who's Who and several other data sources were used to determine the political function of a mediator. We relied on the COW Nation Members of the Interstate System List (1816-1993) to resolve whether a mediator represented an internationally recognized state at the time of appointment. The GDP and population data are based, where possible, on the Penn

\footnotetext{
3 Other mixed teams, that were not too frequent, were attributed to the residual category 'other types'.
}

World Tables (Summer and Heston, 1991) and the World Bank as a secondary source. We used the reported values for the year 1990 and thus for the end of our examination period.

\section{Outsiders and Insiders in the International Mediation Market}

Studies on international mediation traditionally focus on the effectiveness of the mediation attempt as the typical outcome variable (eg. Kleiboer, 1996). This study pushes the theoretical inquiry further by looking at the other side of the coin, namely the conditions that determine the supply and choice of mediators.

Table I offers a first overview of this market and shows that international conflict management is a much more state centric endeavor than some studies on the increasing importance of transnational actors in world politics would have us believe. The reported numbers unambiguously demonstrate that mediation was largely in the hands of diplomats who acted on behalf of their own government rather then in their own private interest during the entire Cold War. The data reported in this 
Table II. Number of Mediation Mandates by Mediator Type and by Decade

\begin{tabular}{lccccr}
\hline Periods & States & IGOs & NGOs & Private Individuals & Total \\
\hline $1950-60$ & 21 & 26 & 0 & 3 & 53 \\
$1960-70$ & 51 & 98 & 7 & 12 & 176 \\
$1970-80$ & 144 & 74 & 8 & 9 & 247 \\
$1980-90$ & 139 & 74 & 14 & 14 & 247 \\
\hline
\end{tabular}

table also suggest that the overall success rate of international mediators is below the average of $36 \%$. It should be repeated that we excluded cases from our analysis in which only mediation was offered.

Table 1 also reveals that mixed mediators are hardly the norm. If one or several states, however, team up with an IGO, then the expected success rate exceeds the average. Of all 723 mediation attempts under consideration, 460 were unsuccessful, while 92 ended in a ceasefire and 128 and 48, respectively, in either a partial or a full settlement. ${ }^{4}$ The analysis reveals that the average effectiveness of the different groups is rather small.

Table II reports how the distribution of mediator types has evolved over time. Although we cover only four decades, we can clearly see that IGOs were initially more active than nation-states. This started to change with the crisis that the UN and, more generally, the multilateral conflict diplomacy had to endure in the 1970s and 1980s. The stronger emphasis on the UN since the end of the Cold War is in some ways a return to the older pattern of conflict management. NGOs, on the other hand, play a rather negligible role in international conflict management, although their importance has been slightly growing throughout the Cold War. Private individuals, finally, were relatively active in the 1960s and 1980, but no clear trend for this type of mediator is observable.

${ }^{4}$ One case - the Egyptian mediation in the Western Sahara in 1978 - could not be classified in the categories that measure effectiveness of international conflict management.
One important aspect of international mediation that we have neglected so far is the size of the occasional mediator groups. Quite often, some actors team up and take over a mandate on the mediation market. Table III reports the number of times that teams of a specific type tried to pacify international relations and the success they had in these collective endeavors. Note that Table III contains information on all different sorts of mediators.

Mixed mediation teams most often consisted of representatives of national governments. Hence, of 355 mandates that were held by states, no less than 80 were conducted by groups of government officials. Only few teams consisting of different IGOs were asked to mediate. Teams made up of IGO and government diplomats were more frequent. If we look at the effectiveness of the mediation attempts, quasi-multilateral attempts tend to be more effective than single-actor interventions. This might be due to the increasing credibility that a multi-actor mediation team has. If we summarize the number of mediations with more than two mediators, the success rate is well above $50 \%$.

If we now turn our attention to the identity of the mediators, it becomes quickly obvious that some states dominate international mediation. Table IV summarizes the number of times that certain nation states were selected on the market for conflict managers.

Unsurprisingly, Table IV demonstrates that the USA was one of the most active conflict managers during the Cold War. This has not changed much since the end of the 
Table III. Size and Effectiveness of Mediation Teams

\begin{tabular}{lccc}
\hline Number of Mediators & Frequency & Relative Share & Effectiveness (\%) \\
\hline 1 & 609 & 84.23 & 35.47 \\
2 & 60 & 8.30 & 35.00 \\
3 & 18 & 2.49 & 55.56 \\
4 & 10 & 1.38 & 80.00 \\
5 & 20 & 2.77 & 25.00 \\
6 & 4 & 0.55 & 50.00 \\
7 & 1 & 0.14 & 0.00 \\
8 & - & - & - \\
9 & 1 & 0.14 & 100.00 \\
Total & 723 & - & - \\
\hline
\end{tabular}

Table IV. Number of Mediations by Country (One-Nation Mediations only)

\begin{tabular}{|c|c|c|c|}
\hline USA & 84 & Thailand & 2 \\
\hline Syria & 31 & Turkey & 2 \\
\hline UK & 16 & Zaire & 2 \\
\hline Saudi Arabia & 14 & Mynamar & 1 \\
\hline India & 12 & Cambodia & 1 \\
\hline France & 11 & Cap Verde & 1 \\
\hline Sudan & 9 & Chile & 1 \\
\hline Egypt & 8 & Columbia & 1 \\
\hline Libya & 6 & Ethiopia & 1 \\
\hline Iran & 5 & Ghana & 1 \\
\hline Soviet Union & 5 & Hungary & 1 \\
\hline Congo & 4 & Iraq & 1 \\
\hline Kuwait & 4 & Ivory Coast & 1 \\
\hline Costa Rica & 3 & Jordan & 1 \\
\hline Indonesia & 3 & Madagascar & 1 \\
\hline Kenya & 3 & Mexico & 1 \\
\hline Somalia & 3 & Niger & 1 \\
\hline Algeria & 2 & Nigeria & 1 \\
\hline Australia & 2 & Pakistan & 1 \\
\hline Austria & 2 & Peru & 1 \\
\hline Canada & 2 & Philippines & 1 \\
\hline Gabon & 2 & Portugal & 1 \\
\hline Italy & 2 & Senegal & 1 \\
\hline Mali & 2 & Switzerland & 1 \\
\hline Marocco & 2 & Tanzania & 1 \\
\hline Romania & 2 & Venezuela & 1 \\
\hline South Africa & 2 & Zambia & 1 \\
\hline Sri Lanka & 2 & & \\
\hline
\end{tabular}

States are defined in accordance with Small \& Singer (1982) (updated version of the nation-state file).

Cold War. If conflict parties turn to a state to settle their conflict, the chance that the USA will be chosen is approximately one in three. This clear result is a first indication that either the hegemony or the reputation variable has to be rather important in our subsequent statistical tests. It should also be noted that the role of the Soviet Union on 
the international mediation market was less prominent. This might reflect a combination of the trustworthiness attributed to democracies, and the power to enforce agreements.

The prominent mediatory role India plays is most likely a consequence of regional hegemony in which no regional conflict is conceivable without an intervention by the most powerful actor. In line with our remarks on colony, France and Great Britain were often involved in settling international disputes. This is in contrast to another permanent member of the Security Council, China, which only became active in international diplomacy after Nixon's visit and the subsequent political opening. Whether the pronounced trade orientation in the Chinese foreign policy is accompanied by an active peace diplomacy in the long run cannot be said from the data analyzed here. It should also be noted that Spain is completely and Portugal nearly completely absent in the mediator market. This indicates that the pure status of an ex-colonial power might not be a sufficiently convincing attribute in the mediator market.

In the competition among IGOs, the UN are the clear frontrunner. Table $\mathrm{V}$ lists the number of mediation mandates by IGOs. The results demonstrate that a number of IGOs, besides the UN, play a very significant role in regional conflict management arrangements. Organizations such as the OAS, the OAU, and the Arab League challenge the hegemonic power of leading states in the area of conflict management. It should be noted, though, that such IGOs offer their services in regional conflicts only, where the parties involved share basic cultural and ideological norms.

\section{An Event Count Model of the Selection of Conflict Managers}

The influence of state characteristics on the choice of mediators will be estimated by
Table V. Number of Mediations by Different IGOs

\begin{tabular}{lr}
\hline UN & 158 \\
OAU & 38 \\
OAS & 26 \\
Arab League & 21 \\
Commonwealth & 8 \\
ICO & 7 \\
Nonaligned Countries & 3 \\
ANAD & 2 \\
ACOM & 2 \\
NATO & 1 \\
OPEC & 1 \\
Cairo Preparatory Conference & 1 \\
Islamic Conference Organisation GOC & 1 \\
EEC & 1 \\
ICJ & 1 \\
Indo/Pakistani Western Boundary Case & \\
$\quad$ Tribunal & 1 \\
\hline
\end{tabular}

using OLS, Poisson, and Generalized Negative Binomial Models. We rely on competing models since the recent debate between Achen (1997) and King (1997) did not lead to a clear indication as to which model should be preferred in the analysis of event counts. ${ }^{5}$ Substantively, the main reason for such a stepwise procedure is the wish to test whether the frequent resort to the USA as a mediator is based on the reputation or the power of this state.

Table VI reports the influence that the various independent variables listed in Equation (1) have on the incidence ratio of mediations by states. First, we conducted the OLS and Poisson regression results and compared, for each estimation type, the results that we obtained if the dependent variables include or exclude the number of team mediations in which a state participated.

The results reported in Table VI easily confirm that OLS is not the proper

\footnotetext{
${ }^{5}$ Cameron \& Trivedi (1998) propose a number of interim models between Poisson and the Negative Binomial. These alternatives are, however, not yet available in standard software.
} 
Table VI. OLS Regressions Models and Poisson Event Count Models of the Impact of Independent Variables on the Demand for Mediation by Nation-States

\begin{tabular}{|c|c|c|c|c|}
\hline & \multicolumn{2}{|c|}{$O L S$} & \multicolumn{2}{|c|}{ Poisson } \\
\hline & (1) & (2) & (3) & (4) \\
\hline \multirow[t]{2}{*}{ Council } & $18.72^{* * *}$ & $6.73^{* * *}$ & $8.23^{* * *}$ & $8.63^{* * *}$ \\
\hline & (3.43) & $(2.20)$ & $(2.02)$ & $(3.28)$ \\
\hline \multirow[t]{2}{*}{ Western bloc } & 5.20 & -0.20 & $5.36^{* * *}$ & 0.50 \\
\hline & $(3.50)$ & $(2.24)$ & $(2.45)$ & $(0.33)$ \\
\hline \multirow[t]{2}{*}{ Nonaligned } & 1.99 & 0.10 & $3.70^{* * *}$ & 1.42 \\
\hline & $(2.03)$ & $(1.30)$ & $(1.30)$ & $(0.68)$ \\
\hline \multirow[t]{2}{*}{ Middle East } & $8.08^{* * *}$ & $5.13^{* * *}$ & $4.86^{* * *}$ & $11.72^{* * *}$ \\
\hline & $(1.74)$ & $(1.12)$ & $(0.69)$ & $(2.66)$ \\
\hline \multirow[t]{2}{*}{ USA } & $92.83^{* * *}$ & $75.74^{* * *}$ & $4.21^{* * *}$ & $10.80^{* * *}$ \\
\hline & $(6.06)$ & $(3.88)$ & $(0.76)$ & $(2.98)$ \\
\hline \multirow[t]{2}{*}{ Colonial Power } & 2.67 & 1.94 & 1.37 & $3.41^{* * *}$ \\
\hline & $(2.77)$ & $(1.77)$ & $(0.37)$ & $(1.42)$ \\
\hline \multirow[t]{2}{*}{ Neutral } & -0.53 & 0.18 & $0.21^{* *}$ & 0.51 \\
\hline & $(2.57)$ & $(1.64)$ & $(0.13)$ & $(0.33)$ \\
\hline \multirow[t]{2}{*}{ Population } & -0.0000007 & 0.00000006 & 1.00 & 1.00 \\
\hline & $(0.0000004)$ & $(0.0000003)$ & $(0.00000004)$ & $(0.00000004)$ \\
\hline \multirow[t]{2}{*}{ GDP } & -0.00016 & -0.0001 & 1.00 & 1.00 \\
\hline & $(0.00016)$ & $(0.0001)$ & $(0.00002)$ & $(0.00003)$ \\
\hline \multirow[t]{2}{*}{ Democracy Score } & 0.12 & 0.16 & 0.98 & 1.13 \\
\hline & $(0.18)$ & $(0.12)$ & $(0.02)$ & $(0.04)$ \\
\hline Constant & $\begin{array}{c}-18.56^{* * *} \\
(4.16)\end{array}$ & $\begin{array}{c}-6.15 \\
(2.66)\end{array}$ & - & - \\
\hline$N$ & 125 & 125 & 125 & 125 \\
\hline Root MSE & 5.29 & 3.38 & - & - \\
\hline Adjusted $R^{2}$ & 0.81 & 0.83 & - & \\
\hline Pseudo $R^{2}$ & & & 0.56 & 0.59 \\
\hline Log likelihood & & & -368.018 & -224.676 \\
\hline
\end{tabular}

${ }^{*} p<0.10,{ }^{* *} p<0.05,{ }^{* * *} p<0.01$. Entries are unstandardized parameter estimates in the case of the OLS estimations and the estimated incidence rate ratios in case of the Poisson models. Standard errors are given in parentheses. Equations (1) and (3) include the team mediations; Equations (2) and (4) exclude the team mediations. The McFadden Likelihood Ratio Index (Pseudo $R^{2}$ ) is calculated according to the following formula:

$$
\text { Pseudo } R^{2}=1-\frac{1 \mathrm{n} L_{\text {fitted model }}}{\ln L_{\text {intercept only model }}}
$$

whereby the fitted model stands for the model presented here and the intercept only model is the model only including the constant. If all estimated coefficient amount to 0 , Pseudo $R^{2}$ is equally zero.

approach to estimate event count models. Despite a very high explained variance in the OLS model, many more independent variables prove to be influential in the Poisson model. ${ }^{6}$ This is not the least due to

${ }^{6}$ The corresponding results are not reported in detail here, but can be obtained from the authors upon request. If we exclude the US dummy from the OLS regression, the explained variance only amounts to $40 \%$ instead of the $80 \%$ reported here. the fact that event count models reduce the range of the standard error in comparison to OLS. ${ }^{7}$ Substantively, the models show that the hegemony variable has a pronounced effect on the number of mediation mandates a state receives in the international market

\footnotetext{
${ }^{7}$ It should also be noted that Poisson, in contrast to other event count models, might entail inflated $t$-ratios (Cameron \& Trivedi, 1998).
} 
for mediation. The incidence rate ratio for this variable suggests that the mediation rate of a Western Superpower was more than four times as large as that of the competing states.

We can equally observe a clear impact of the permanent membership in the Security Council on the number of mediations. If a state becomes elected to this exclusive club, its government can sooner or later count on the possibility to act as an international conflict manager. Note again that China is the only permanent member which was not chosen as a mediator in the period under examination. Colonial powers, by contrast, seem only to be in demand if they pursue their mediation mandate unilaterally. In Equation (3), the impact of the corresponding independent variable is insignificant while in Equation (4) such an influence exists. Yet, power considerations are not the only factor that matters on the international mediation market. An almost equally important impact involves the Middle Eastern dummy. This shows that a tendency to appoint mediators with a common cultural background exists in the most conflictridden region of the world. The analysis generally suggests that such cultural variables still have an influence even if we control for a substantive number of power-related variables. Our analysis also confirms the earlier finding of Marquis and Schneider (1996), who demonstrated that a formal neutrality policy is not necessarily a desirable attribute in the mediation market.

Our estimations do not yet allow any firm conclusion as to whether reputation or hegemonic power is ultimately more important. We turn now to this issue in our discussion of the results obtained from the negative binomial regression. We will compare the results that we obtain from estimations of the basic model with and without the USA.

The results reported in Table VII show that the market for mediation is influenced by factors that we did not yet uncover in the previous estimations. Equations (1) and (2) suggest that reputation, as measured by the average effectiveness of the mediation attempts, rather reduces the relative incidence ratios. This is indicated by the entries which are smaller than one. In other words, conflict parties do not seem to be much concerned about the track record of the states which they invite to act as mediators. The negative result, however, does not directly imply that the market favors badly reputed mediators. We suspect that the market for mediators is less stable than is assumed. Table IV shows that more than 30 mediators only appear once or twice on the market and that subsequently they disappear. The statistical impact of this short-run demand is the reduction in the incidence rate ratio. On a more theoretical level, this suggests that the market for mediation follows certain fashions and situational aspects. Actors who are in demand in the 1950s might well be forgotten some years later.

The results that we obtained with the Generalized Negative Binomial regressions are much less convincing than the estimations produced by the Poisson models. Since the pseudo $R^{2}$ is much smaller, it was much harder to find a good maximum likelihood estimation of the data. The smaller number of independent variables that have an influence on the number of mediations per country is a further indication of this trend.

\section{Conclusion}

This paper has analyzed international mediation in terms of a market dominated by a number of actors. We feel that the key to understanding the process of mediation is to identify the attributes of those actors who are most likely to mediate in international relations. We have shown that a few 
Table VII. Negative Binomial Regression Models of the Impact on the Demand for Mediation by Nation-States

\begin{tabular}{lcccc}
\hline & \multicolumn{2}{c}{ With USA dummy } & \multicolumn{2}{c}{ Without USA dummy } \\
& $(1)$ & $(2)$ & $(3)$ & $(4)$ \\
\hline Council & $19.01^{* * *}$ & $16.97^{* * *}$ & $28.59^{* * *}$ & $34.23^{* * *}$ \\
Western Bloc & $(21.10)$ & $(18.23)$ & $(27.44)$ & $(38.43)$ \\
& $129.71^{* * *}$ & 8.51 & $169.92^{* * *}$ & 13.37 \\
Nonaligned & $(222.53)$ & $(13.14)$ & $(286.59)$ & $(22.04)$ \\
& $16.31^{* *}$ & 5.72 & $21.69^{* * *}$ & $9.23^{* *}$ \\
Middle East & $(18.30)$ & $(6.12)$ & $(22.39)$ & $(10.27)$ \\
& $2.90^{* * *}$ & $6.88^{* * *}$ & $2.86^{* * *}$ & $6.31^{* * *}$ \\
USA & $(1.00)$ & $(3.56)$ & $(0.98)$ & $(3.30)$ \\
& 2.62 & 7.68 & - & - \\
Colonial Power & $(4.38)$ & $(12.76)$ & & 0.84 \\
Neutral & 0.27 & 0.73 & 0.28 & $(1.02)$ \\
Population & $(0.35)$ & $(0.84)$ & $(0.37)$ & 0.88 \\
& 0.64 & 0.98 & 0.62 & $(1.03)$ \\
GDP & $(0.75)$ & $(1.12)$ & $(0.73)$ & 1.00 \\
& 1.00 & 1.00 & 1.00 & $(0.0000002)$ \\
Democracy Score & $(0.0000002)$ & $(0.0000002)$ & $(0.0000002)$ & 1.00 \\
& 1.00 & 1.00 & 1.00 & $(0.00007)$ \\
Inalpha Reputation & $(0.00005)$ & $(0.00007)$ & $(0.00005)$ & $(0.01$ \\
& 0.94 & 1.03 & 0.94 & $0.08)$ \\
$N$ & $(0.05)$ & $(0.08)$ & $(0.05)$ & $0.16^{* *}$ \\
Pseudo $R^{2}$ & $0.002^{* * *}$ & & & $(0.14)$ \\
Log likelihood & $(0.002)$ & $0.18^{*}$ & $0.002^{* * *}$ & 125 \\
\hline & 125 & $(.016)$ & $(0.002)$ & -166.79 \\
\hline
\end{tabular}

${ }^{*} p<0.10,{ }^{* *} p<0.05,{ }^{* * *} p<0.01$. Entries are unstandardized parameter estimates in the case of the OLS estimations and the estimated incidence rate ratios in case of the Poisson models. Standard errors are given in parentheses. Equations (1) and (3) include the team mediations; Equations (2) and (4) exclude the team mediations. The McFadden Likelihood Ratio Index (Pseudo $R^{2}$ ) is calculated according to the following formula:

$$
\text { Pseudo } R^{2}=1-\frac{1 \mathrm{n} L \text { fitted model }}{\ln L \text { intercept only model }}
$$

whereby the fitted model stands for the model presented here and the intercept only model is the model only including the constant. If all estimated coefficient amount to 0 , Pseudo $R^{2}$ is equally zero.

powerful states and IGOs dominate international conflict management. Most importantly, the number of times an actor mediates does not depend on its reputation for success. This means that the market for mediation follows certain fashions which promote some states for a certain period until they are no longer considered to be important actors. Yet, this short-term demand is a function of a state's power and influence at that time, and not of its effectiveness in the mediation market. Furthermore, an official policy of neutrality is not so big an asset in a mediator's portfolio in militarized disputes. On the contrary, a permanent seat on the Security Council, for example, is a much more significant factor affecting the choice of mediators. 
We believe that some of these results have important implications for our understanding of international conflict management. First, while the results partly support hegemony theory (Lake, 1994), the analysis also demonstrates that international conflict management is not only influenced by power considerations. Although the Superpowers of the Cold War era and other permanent members of the Security Council are very much more likely to become active in an international conflict, the USA is not the sole dominating force in this market. Second, the analysis demonstrates the need for a more rigorous study of international conflict management which is still largely characterized by ad hoc theories and casual empirical illustrations. Our article has attempted to hone home the message that even a very simplistic expected-utility model is able to offer major theoretical implications. On a methodological level, the analysis shows how a comparison between traditional OLS regression analysis and the more adequate event count models can lead to interesting theoretical insights.

Our results open up interesting avenues for further research. One immediate question is the interconnection between specific conflict characteristics and the selection of international mediators. We do not yet know the circumstances under which the conflict parties agree to a mediation at all and then, once this initial choice is made, to a multilateral rather than a unilateral form of conflict management. The preliminary evidence suggests that small states are only likely to receive mandates if the more powerful mediators have not been successful (Marquis and Schneider 1996). Yet, the eagerness of at least some states to receive such a risky mandate demonstrates again that a political economy framework is a powerful tool for the systematic analysis of international conflict management.

\section{References}

Achen, Christopher A., 1996. 'Implicit Substantive Assumptions Underlying the Generalized Event Count Estimator', Political Analysis 6(2): 155-173.

Arruch, Kevin, 1998. Washington, DC: United States Institute of Peace Press. Culture and Conflict Resolution. Washington, DC: United States Institute of Peace Press.

Benoit, Kenneth, 1996. 'Democracies Really Are More Pacific (in General). Reexamining Regime Type and War Involvement', Journal of Conflict Resolution 40(4): 636-657.

Bercovitch, Jacob, 1984. Social Conflicts and Third Parties: Strategies of Conflict Resolution. Boulder, CO: Westview Press.

Bercovitch, Jacob, 1986. 'International Mediation: A Study of Incidence, Strategies and Conditions of Successful Outcomes', Cooperation and Conflict 21: 155-168.

Bercovitch, Jacob, 1989. 'International Dispute Mediation', in K. Kressel \& D. G. Pruitt, eds, Mediation Research: The Process and Effectiveness of Third Party Intervention. San Francisco, CA: Jossey Bass.

Bercovitch, Jacob \& R. Wells, 1993. 'Evaluating Mediation Strategies: A Theoretical and Empirical Analysis', Peace and Change 18: 3-25.

Bercovitch, Jacob, J. T. Agnoson \& D. Wille, 1991. 'Some Contextual Issues and Empirical Trends in the Study of Successful Mediation in International Relations', Journal of Peace Research 28: 7-17.

Brookmire, D. \& F. Sistrunk, 1980. 'The Effects of Perceived Ability and Impartiality of Mediator and Time Pressure on Negotiation', Journal of Conflict Resolution, 24(3): 311-327

Cameron, Colin \& Pravin K. Trivedi, 1998. Regression Analysis of Count Data. Cambridge: Cambridge University Press.

Cohen, R., 1996. 'Cultural Aspects of International Mediation', in Jacob Bercovitch, ed., Resolving International Conflicts. Boulder: Lynne Rienner (107-128).

Edmead, F., 1971. Analysis and Prediction in International Mediation. New York: UNITAR Study.

Elgstrom, Ole, 1994. 'National Culture and International Negotiation', Cooperation and Conflict 29(3): 289-301. 
Faure, G., 1989. 'The Mediators as Third Negotiators', in E. Mautner-Markhof, ed., Process of International Negotiation. Boulder, CO: Westview Press (415-426).

Frei, Daniel, 1976. 'Conditions Affecting the Effectiveness of International Mediation', Peace Science (Society) Papers International 26(1): 67-84

Goertz, Gary, ed., 1997. 'Conflict Management and Termination in International Rivalry', International Interactions (Special Issue) 22(4): 321-340.

Gross-Stein, Janice, 1985. 'Structure, Strategies and Tactics of Mediation: Kissinger and Carter in the Middle East', Negotiation Journal 1(3): 331-347

Jackson, E., 1952. Meeting of Minds. New York: McGraw-Hill.

Karim, A. \& R. Pegnetter, 1983. 'Mediator Strategies, Qualities and Mediation Effectiveness', Industrial Relations 22(1): 105-14.

Kaufman, Sanda \& George T. Duncan, 1992. 'A Formal Framework for Mediator Mechanisms and Mediations', Journal of Conflict Resolution 36(4): 688-708.

King, Gary, 1989a. Unifying Political Methodology. The Likelihood Theory of Statistical Inference. Cambridge, UK: Cambridge University Press.

King, Gary, 1989b. 'Event Count Models for International Relations', International Studies Quarterly 33(1): 123-147.

King, Gary \& Curtis S. Signorino, 1997. 'The Generalization in the Generalized Event Count Model, with Comments on Achen, Amato, and Londregan', Political Analysis 6(2): 225-252.

Kleiboer, Marieke, 1996. 'Understanding Success and Failure of International Mediation', Journal of Conflict Resolution 41(3): 360389.

Krain, Matthew, 1998. 'Contemporary Democracies Revisited. Democracy, Political Violence and Event Count Models', Comparative Political Studies 31(2): 139-164.

Kressel, K. \& D. G. Pruitt, eds, 1989. Mediation Research: The Process and Effectiveness of Third Party Intervention. San Francisco, CA: Jossey Bass.

Lake, David, 1994. 'Leadership, Hegemony, and the International Economy: Naked Emperor or Tattered Monarch with Potential?', International Studies Quarterly 37(4): 459489.

Marquis, Lionel \& Gerald Schneider, 1996. 'Wer kommt als Vermittler zum Zuge? Überschätzte und unterschätzte Anforderungsfaktoren für Mediationstätigkeiten' [Who is Chosen as a Mediator? Overestimated and Underestimated Prerequisites of Conflict Management Activities]. Swiss Political Science Review 2(3): 69-82.

Ninic, Miroslav, 1992. Democracy and Foreign Policy: The Fallacy of Political Realism. New York: Columbia University Press.

Northedge, F. \& M. Donelan, 1971. International Disputes: The Political Aspects. London: Europa Publications

Ott, M. C., 1972. 'Mediation as a Method of Conflict Resolution', International Organization 26(4): 595-618.

Princen, Thomas, 1992. Intermediaries in International Conflict. Princeton, NJ: Princeton University Press.

Pruitt, D. G. \& D. F. Johnson, 1970. 'Mediation as an Aid to Face- Saving in Negotiation', Journal of Personality and Social Psychology 14(2): 239-246

Regan, Patrick M., 1996. 'Conditions of Successful Third Party Intervention in Intrastate Conflicts', Journal of Conflict Resolution 40(3): 336-359.

Small, Melvin \& J. David Singer, 1982. Resort to Arms: International and Civil Wars, 1816-1980. Beverly Hills, CA: SAGE.

Smith, W. P., (1985). 'Effectiveness of the Biased Mediator', Negotiation Journal 1(3): 363372.

Summer, Robert \& Alan Heston, 1991. 'The Penn World Table (Mark 5): An Expanded Set of International Comparisons, 19501988', Quarterly Journal of Economics 106(2): 327-386.

Susskind, L. \& L. Cruishank, 1987. Breaking the Impasse. New York: Basic Books.

Touval, S., 1985. 'The Context of Mediation', Negotiation Journal, 1(3): 373-378.

Touval S. \& I. W. Zartman, eds, 1985. International Mediation in Theory and Practice. Boulder, CO: Westview Press. 
Wehr, P., 1979. Conflict Regulation. Boulder, CO: Westview.

Young, O. R., 1967. Intermediaries: Third Parties in International Crises. Princeton, NJ: Princeton University Press.

Young, O. R., 1972. 'Intermediaries: Additional Thoughts on Third Parties', Journal of Confict Resolution, 16(1): 51-56.
JACOB BERCOVITCH, b. 1947, PhD (1980); Professor of International Relations at the University of Canterbury, New Zealand (1981-2000). Current research interests: international conflict resolution and mediation.

GERALD SCHNEIDER, b. 1962, PhD (1991); Professor of Political Science at the Faculty of Public Policy and Management of the University of Konstanz (1997); Executive Editor of European Union Politics. 